\title{
The effect of Streptococcus mutans on the Corrosion Behavior of Nickel-Titanium Dental Alloys - In Vitro Study
}

\author{
Asmaa Marda 1,*, Khadija Mouflih ${ }^{2}$, Abdelkabir Bellaouchou ${ }^{2}$, Abdallah Guenbour ${ }^{2}$, Asmae \\ Elmansari $^{3}$, Karim Souly ${ }^{4}$, Mimoun Zouhdi ${ }^{4}$, Fatima Zaoui ${ }^{5}$, Loubna Bahije ${ }^{5}$ \\ ${ }^{1}$ Research Team in Microbiology, Faculty of Medicine and Pharmacy, Mohamed V University, Rabat, \\ BP 6203, Morocco \\ ${ }^{2}$ Laboratory of Materials, Nanotechnology and Environment, Mohammed V University in Rabat, \\ Faculty of Sciences Morocco \\ ${ }^{3}$ Faculty of Dental Medicine graduate, Mohammed V University, Rabat, Morocco \\ ${ }^{4}$ Laboratory of Microbiology, Ibn Sina University Medical Center of Rabat, 10100, Morocco \\ ${ }^{5}$ Department of Research in Biomaterials and Saliva Biomarkers, Faculty of Dental Medicine, \\ Mohammed V University, Rabat, BP 6212 Morocco
}

\begin{abstract}
This study aimed to compare the resistance of dental alloys to corrosion in a solution containing oral bacteria named Streptococcus mutans (S.mutans). The electrochemical behavior of Nickel-Titanium (NiTi) was investigated in sterile Fusayama artificial saliva (AS) with the enrichment medium tryptic soy broth (TSB) in solution 1 and (AS) with (TSB) and bacteria in solution 2. The electrochemical procedures selected for this work were open circuit potentials (OCP), Potentiodynamic polarization (PDP), and electrochemical impedance spectroscopy (EIS). The NiTi surface was examined using optical microscopy.
\end{abstract}

After 24 hours of immersion in artificial saliva, the results have shown that NiTi revealed high corrosion reactivity in the presence of $S$. mutans and present pitting corrosion on the surface.

Keywords: Streptococcus mutans; Dental alloys; Nickel Titanium; Corrosion.

\section{Introduction}

Biofilms are communities of microorganisms that expand on many solid environmental surfaces of the human body ${ }^{1,2}$. Dental plaque in the oral cavity is one of the biofilms slightly studied in the human body. More than 700 different species coexist with the healthy flora of the oral cavity ${ }^{2}$. This growth in the number of microorganisms is the result of several conditions in the mouth, including $\mathrm{pH}$ scale, warmth and moisture ${ }^{3}$. The oral cavity is composed of nonstable structures such as tissues that can be renewed, and stable structures such as teeth. The latter helps in the formation of dental plaque biofilms ${ }^{4}$.

The tooth consists of smaller sub-environments where certain species colonize and predominate based on their metabolic requirements. The supragingival plaque which lies above the gingival line of the tooth surface consists of aerobic microorganisms that can cause caries, while the subgingival plaque, which is found below the gingival line, consists of anaerobic species that cause periodontal disease ${ }^{3,5}$.

Though specific types of acid-producing bacteria may promote the breakdown of hard tooth structures or restorative materials such as orthodontic archwires or dental amalgams; they may also be degraded during a biocorrosion process ${ }^{6}$. Among the several microorganisms present in the oral cavity, Streptococcus mutans is one of the essential bacteria because of its ability to convert sugar into lactic acid, and contribute to tooth decay ${ }^{7}$. Moreover, an oral biofilm containing a high proportion of $\mathrm{S}$. mutans can develop in aerobic and anaerobic environments and can be found in different habitats of the oral cavity, this species causes a decrease in $\mathrm{pH}$ of the oral cavity ${ }^{8}$, which promotes demineralization enamel, decay and also corrosion of dental materials ${ }^{7}$.

Thus bacterium is considered a robust corrosive microorganism.

In dentistry, Nickel-Titanium is the first choice for oral malocclusions and is used as a fixed dental wire because of its good resistance to corrosion, low density, and high mechanical strength. Compared to

other orthodontic alloys, its Biocompatibility and super elasticity provide a light and continuous force to ensure physiological and practical teeth movements ${ }^{9}$. NiTi is a material with high resistance to corrosion 
compared to other metallic materials in oral rehabilitation ${ }^{10}$. However, the dissolution of the NiTi film may occur in certain media such as those containing high fluoride concentrations, Hydrogen peroxide $\left(\mathrm{H}_{2} \mathrm{O}_{2}\right)$, and lactic acid. It can also occur in the oral cavity ${ }^{11}$. Moreover, the corrosion of titanium increases when $\mathrm{F}-, \mathrm{H}_{2} \mathrm{O}_{2}$ and lactic acid are combined, as revealed by Mabilleau and al. ${ }^{11}$. Corrosion of the titanium causes the release of metal ions into the oral cavity that may stimulate an initial inflammatory response, and a consequent toxic, mutagenic and/or carcinogenic reaction, if the corrosion was severe, the effect may be visible in vivo, resulting in a change of surface coloration or gingival inflammation ${ }^{12}$.

In literature, several investigations studied the behavior of nickel-titanium in the presence of cariogenic bacterium S. mutans. Bahije et al. ${ }^{13}$. Observed a high degree of corrosion of NiTi orthodontic wire in the presence of $S$. mutans during two hours of immersion. Then, they recommended further investigations with an extension of the dental alloy immersion time in the presence of bacteria. Souza et al. ${ }^{12}$ showed that the presence of bacterial colonies, such as $S$. mutans, negatively affected the corrosion resistance of the titanium.
The purpose of this study was, therefore, to draw a comparison between the electrochemical behavior of NiTi dental alloy in artificial saliva with or without the $S$. mutans bacteria.

\section{Materials and methods}

\section{Material}

The test specimen used in this study is NiTi orthodontic wire (55\% nickel and $45 \%$ titanium, G\&H Wire Company). The sample dimension for the tested material was $0.016 \mathrm{~mm} \times 0.022 \mathrm{~mm}$, with $15 \mathrm{~mm}$ of wires exposed at each end. Therefore, the exposed surface was $0.011 \mathrm{~cm}^{2}$. Samples had not undergone any surface treatment.

\section{Preparation of the media}

Two media were used in the study: Solution 1, contains Fusayama artificial saliva (AS) ${ }^{14}$; the composition is shown in (Table 1). With the enrichment medium tryptic soy broth (TSB) of (Becton, Dickinson $\mathrm{BD}^{\mathrm{TM}}$ ), this solution was sterilized at 121 to $124{ }^{\circ} \mathrm{C}$ for $15 \mathrm{~min}$. Solution 2 contains AS, TSB and $S$. mutans.

Table 1. Composition of the Fusayama solution.

\begin{tabular}{|c|c|c|c|c|c|}
\hline $\mathbf{K C l}$ & $\mathrm{NaCl}$ & $\mathrm{CaCl}_{2} .2 \mathrm{H}_{2} \mathrm{O}$ & $\mathrm{NaH}_{2} \mathrm{PO}_{4} .2 \mathrm{H}_{2} \mathrm{O}$ & $\mathrm{Na}_{2} \mathrm{~S}_{.9 H_{2}} \mathrm{O}$ & Urea \\
\hline $0.4 \mathrm{~g} / \mathrm{L}$ & $0.4 \mathrm{~g} / \mathrm{L}$ & $0.906 \mathrm{~g} / \mathrm{L}$ & $0.690 \mathrm{~g} / \mathrm{L}$ & $0.005 \mathrm{~g} / \mathrm{L}$ & $1 \mathrm{~g} / \mathrm{L}$ \\
\hline
\end{tabular}

\section{Bacterial strains and growth conditions}

The lyophilized strain S. mutans 19305CIP 103220 of (CRBIP) was rehydrated with $0,2 \mathrm{ml}$ of nutrient broth brain heart infusion (BHI) of GranuCult ${ }^{\circledR}$ after it was microaerophilically grown for 48 hours at $37^{\circ} \mathrm{C}$ in agar plates with $32 \mathrm{~g} / 1$ of mutans agar and 0.2 units of both bacitracin and sucrose were added (final concentration: 20\%).

The bacterial cells were inoculated in TSB for $18 \mathrm{~h}$ at $37^{\circ} \mathrm{C}$ and $150 \mathrm{rpm}$. After incubation, cells were harvested by centrifugation for $10 \mathrm{~min}$ at $4{ }^{\circ} \mathrm{C}$ and $5000 \mathrm{rpm}$ and washed twice with a phosphate buffer solution (PBS). The purity of the strain was checked using the automaton Phoenix (Becton Dickinson Phoenix 100 Microbiology Automaton $($ Sogemed). The prepared cultures were added to a cell containing $60 \mathrm{ml}$ of AS.

\section{Electrochemical techniques}

All experiments were conducted in a glass electrochemical glass vessel with a Met Rohm hermetically sealed doubled glass wall, with the thermostat set at $37{ }^{\circ} \mathrm{C}$. The standard three-electrode system was adopted. The working electrode was the $\mathrm{NiTi}$ wire, the counter-electrode was rectangular platinum (Radiometer Analytical), and the reference electrode was a Mercury/mercurous sulphate $\left(\mathrm{Hg} / \mathrm{Hg}_{2} \mathrm{SO}_{4} / \mathrm{K}_{2} \mathrm{SO}_{4}\right.$ saturated, Radiometer Analytical, $0.641 \mathrm{~V}$ vs SHE). In order to keep the cell sterile, all openings were sealed to allow air to enter without contaminating the solution. The cell and the electrodes were sterilized. The entire apparatus was connected to a computer-driven PGZ 301 potentiostat under Volta Master 4 software.

The samples treated with Solutions were studied by conducting open circuit potential (OCP), Potentiodynamic polarization (PDP), and electrochemical impedance spectroscopy (EIS) measurements.

Corrosion parameters, including OCPs, corrosion current densities $\left(\mathrm{I}_{\text {corr }}\right)$, and charge transfer resistance values $\left(R_{c t}\right)$ obtained from the electrochemical measurements were used to evaluate the corrosion resistance of the studied alloys.

OCPs were measured for 2 hours, after an immersion time of 24 hours of the test specimen in the electrolyte solution. Impedance spectroscopy was measured over a range of frequency of $100 \mathrm{kHz}$ to 100 $\mathrm{MHz}$, with a frequency of 10 points per decade, and a sine wave voltage amplitude of $10 \mathrm{mV}$ ). The diagrams in the Nyquist plane were analyzed to determine the $\left(\mathrm{R}_{\mathrm{ct}}\right)$ and describe the behavior of the substratesolution interface. Potentiodynamic polarization 
curves were recorded in the scan range between -1000 to $1000 \mathrm{mV}$ (vs OCP) at a scanning rate of $1 \mathrm{mV} / \mathrm{s}$. The $I_{\text {corr }}$ values were calculated using the Tafel method.

\section{Surface analysis}

The surface of the NiTi archwire was examined using optical microscopy (OM) (Leica DM $6000 \mathrm{M}$ ). NiTi was immersed in solution 1 and 2 at $37{ }^{\circ} \mathrm{C}$, for 216 hours. After that, the specimens were washed gently with phosphate buffer solution (PBS), then dried carefully and examined.

\section{Open circuit potential (EocP) measurements}

The OCP values obtained from NiTi alloy and treated in the two solutions at $37^{\circ} \mathrm{C}$ are traced through time, as shown in (Fig. 1). The OCP of the NiTi alloy treated with solution 1 for 2 hours was stabilized at $0.641 \mathrm{VmV}$ (vs. $\mathrm{Hg} / \mathrm{Hg}_{2} \mathrm{SO}_{4}$ ), while the OCP value in the presence of $S$. mutans decreases to $-0.968 \mathrm{mV}$ (vs. $\mathrm{Hg} / \mathrm{Hg}_{2} \mathrm{SO}_{4}$ ). This electrochemical behavior witnessed an increase in NiTi's reactivity that may indicate a higher corrosion activity in the presence of bacterial biofilm ${ }^{12}$.

\section{Result}

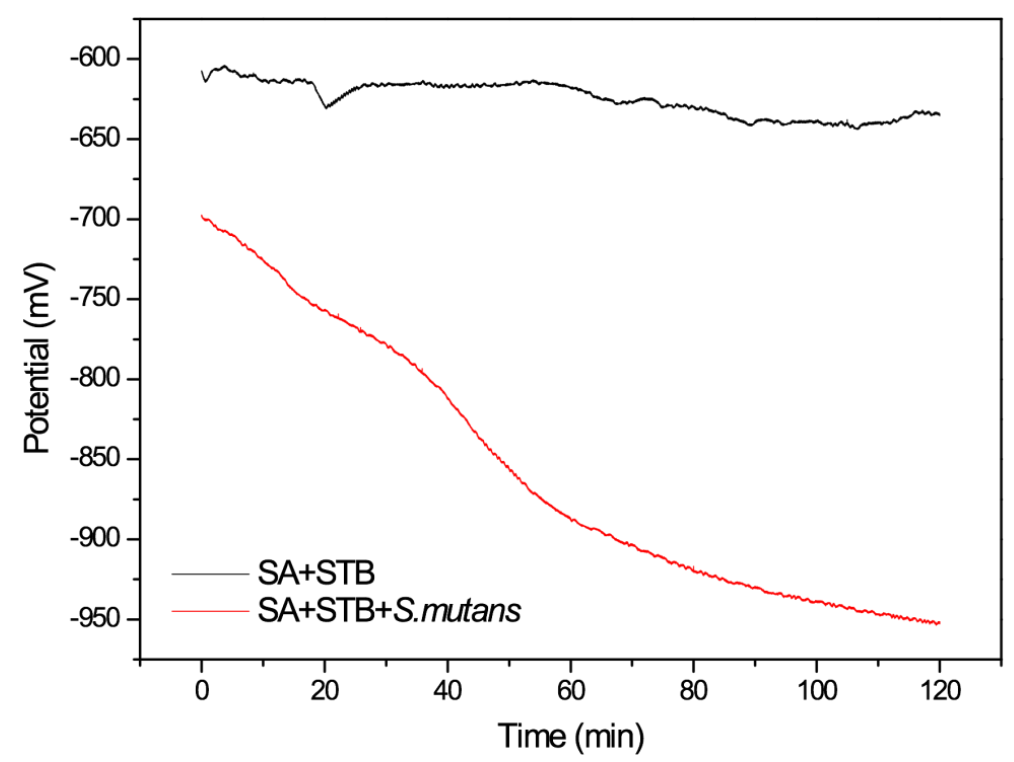

Figure 1. OCP curves obtained for NiTi alloy treated in Solutions 1 and 2 at $37^{\circ} \mathrm{C}$

\section{Polarization curves}

(Fig. 2) shows the potentiodynamic polarization curves for NiTi in both studied solutions, while (Table 2) summarizes corrosion parameters.

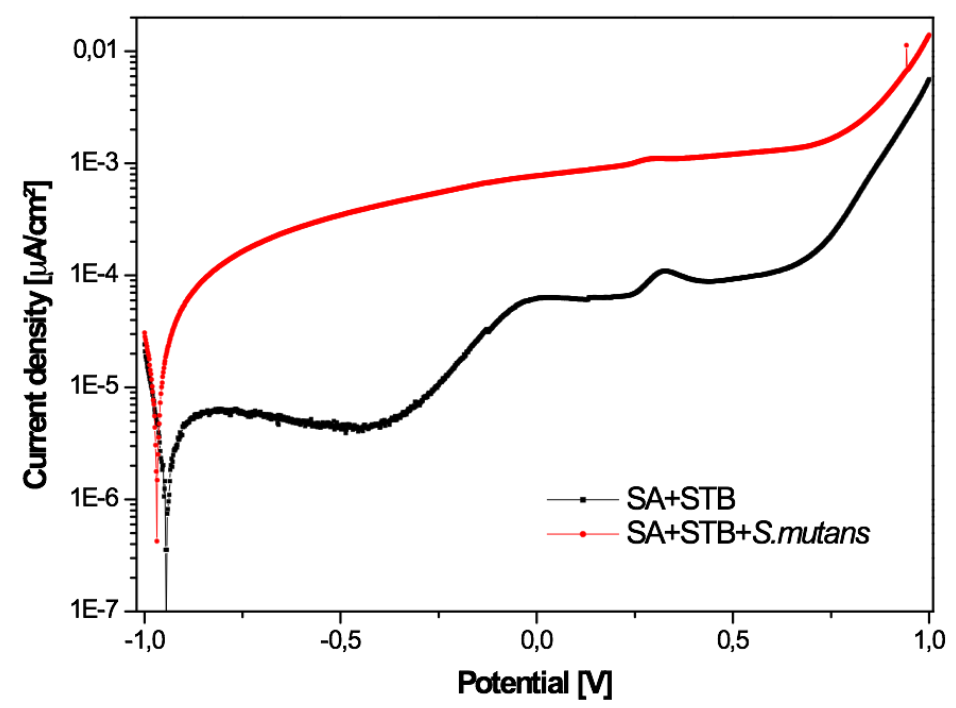

Figure 2._Potentiodynamic polarization curves for NiTi after $24 \mathrm{~h}$ of immersion in both studied solutions

Generally, in the cathodic potential domain, we observe competition between oxygen reduction and hydrogen reduction. The anodic polarization domain presents a monotonous increase in current density, 
pointing to the dissolution of the alloy ${ }^{15}$, followed by a plateau. The plateau indicates the formation of a

layer of corrosion products, consisting mainly of $\mathrm{TiO}_{2}$ 12 .

Table 2. Electrochemical parameters of NiTi in the two media.

\begin{tabular}{|c|c|c|c|}
\hline $\begin{array}{c}\text { Electrochemical } \\
\text { parameters }\end{array}$ & $\mathbf{E}_{\text {ocp }} \mathbf{~ m V}$ vs. $\mathbf{H g} / \mathbf{H g}_{2} \mathbf{S O}_{4}$ & $\mathbf{I}_{\text {corr }} \boldsymbol{\mu A . \mathbf { c m } ^ { 2 }}$ & $\mathbf{E}_{\text {corr }} \mathbf{~ m V ~ v s . ~} \mathbf{H g}_{\mathbf{H}} \mathbf{H g}_{2} \mathbf{S O}_{4}$ \\
\hline AS + STB & -641 & 4.07 & -945 \\
\hline AS + STB + S. mutans & -968 & 58.20 & -965 \\
\hline
\end{tabular}

As reported in (Table 2), when $S$. mutans was added, the corrosion potential decreased from -945 $\mathrm{mV}$ vs $\mathrm{Hg} / \mathrm{Hg}_{2} \mathrm{SO}_{4}$ to $-965 \mathrm{mV}$ vs $\mathrm{Hg} / \mathrm{Hg}_{2} \mathrm{SO}_{4}$ and the corrosion current $\mathrm{I}_{\text {corr }}$ values increased from 4.07 $\mu \mathrm{A} . \mathrm{cm}^{-2}$ to $58.2 \mu \mathrm{A} . \mathrm{cm}^{-2}$. Thus, polarization study revealed a decrease in the NiTi dental alloy's corrosion resistance when immersed in the artificial saliva in the presence of $S$. mutans.

\section{Electrochemical impedance spectroscopy measurements}

Fig. 2 shows the electrochemical impedance spectroscopy data obtained from the samples immersed in solutions 1 and 2 for 24 hours.

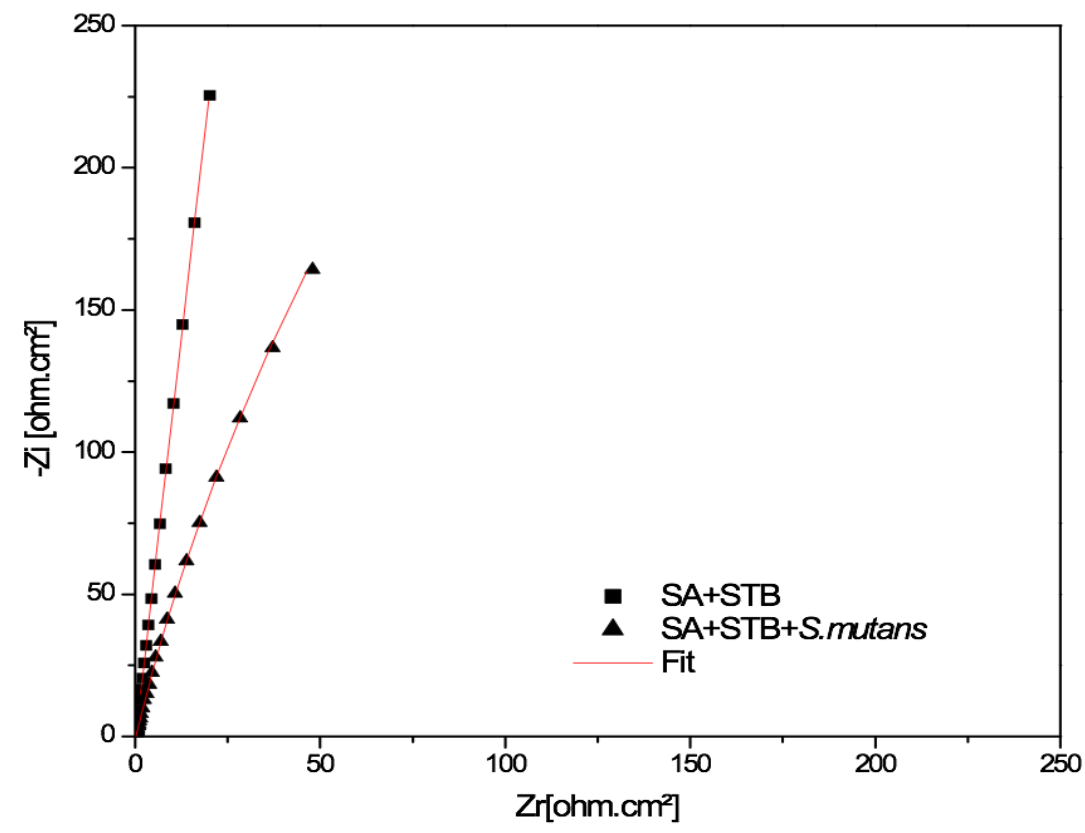

Figure 3. Nyquist plots obtained for the NiTi alloy treated in solutions 1 and 2 at $37^{\circ} \mathrm{C}$.

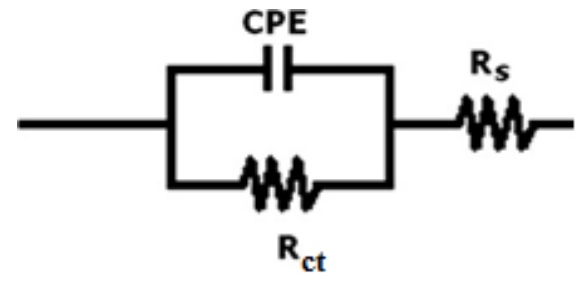

Figure 4. Electrical equivalent circuit for the fitting of EIS data

The Nyquist diagram displays a single-phase capacitor arc in the complex plane with its diameter decreasing in the presence of $S$. mutans. The AC impedance parameters derived from Nyquist plots are given in Table 3. Fig. 4 shows the electrical equivalent circuit for EIS measurements in our study. $\mathrm{R}_{\mathrm{ct}}$ was the charge transfer resistance, while CPE was the constant phase element and $\mathrm{R}_{\mathrm{s}}$ referred the solution resistance.

Table 3. Electrochemical impedance spectroscopy parameters of NiTi in the two medium. 


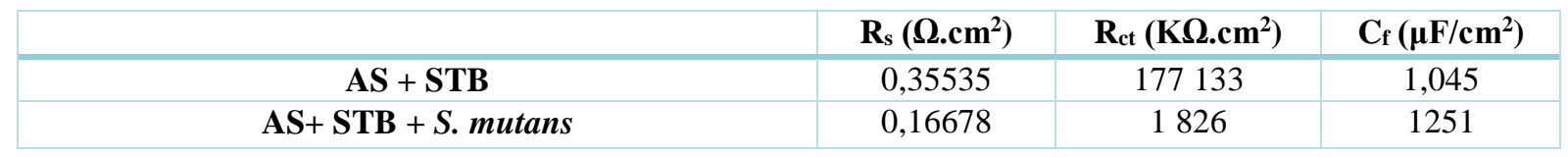

The Nyquist plots of the NiTi alloy immersed in AS containing $S$. mutans show that the charge transfer resistance $R_{c t}$ decreases from 177133 to 1826 $\mathrm{K} \Omega . \mathrm{cm}^{2}$. The capacitance of the double layer $\mathrm{C}_{\mathrm{dl}}$ value increases from 1.045 to $1251 \mu \mathrm{F} / \mathrm{cm}^{2}$. In accordance of to the EIS data, following the linear polarization and EIS analysis results, it can be concluded that the presence of $S$. mutans accelerates the corrosion rate of NiTi orthodontic alloy, both electrochemical methods correlate with each other and present the same conclusion.

\section{Surface analysis}

The OM results are shown in Fig. 5. In the presence of $S$. mutans, the dental alloy surface immersed in artificial saliva for $216 \mathrm{~h}$, showed pitting corrosion (Fig.5b), which is not the case for the dental alloy immersed in artificial saliva without $S$. mutans (Fig.5a).

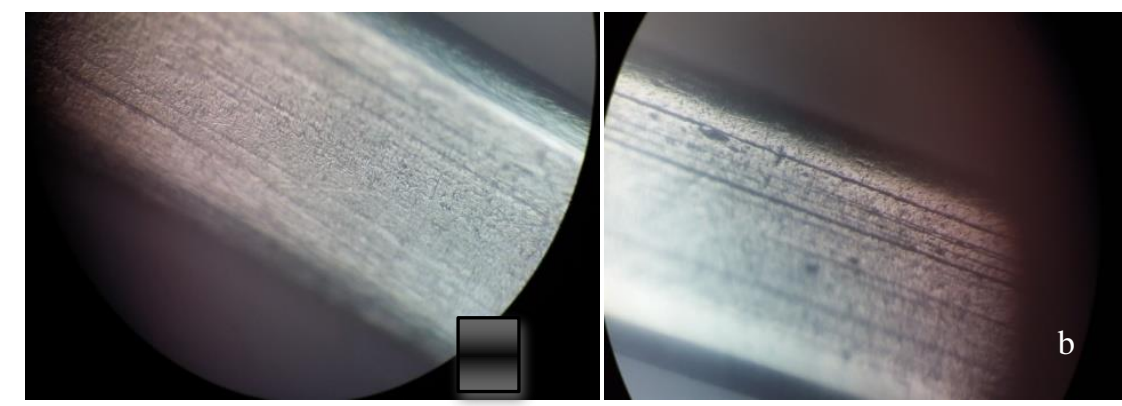

Figure 5. OM images of the alloy samples (a) NiTi exposed to the mixture of AS without S. mutans (b) NiTi exposed to the mixture of AS with $S$. mutans for $216 \mathrm{~h}$.

\section{Discussion}

This study was conducted to study the electrochemical behavior of a NiTi dental alloy that is widely used in dentistry to correct malocclusions, with the presence of $S$. mutans bacteria, over an immersion period of 24 hours. To duplicate the human oral environment as much as possible, we used Fusayama's artificial saliva.

When the metals are immersed in tested solutions, electrochemical reactions occur at the metal solution interface. In this study, the electrochemical measurements of the tested samples revealed a decrease in the corrosion resistance of the NiTi dental alloy in the presence of S. mutans. Chang and al. ${ }^{16}$, have obtained similar results for pure metal $\mathrm{Ti}$, and they explained these findings by the fact that $S$. mutans can metabolize intracellular glycogen to lactic acid. The production of lactic acid from intracellular fermentation can be used to explain why S. mutans can influence the metal's behavior. Souza and al. ${ }^{12}$, found that electrochemical tests indicated an increase in the chemical reactivity of titanium or an increase in the sensitivity to corrosion of titanium in the presence of biofilms. Impedance tests confirmed the polarization results, indicating a decrease in corrosion resistance in the presence of $S$. mutans. Bahije and al. 13, conducted a similar study with a 5 hours' immersion period of the NiTi alloy in a solution containing the bacterium and revealing a more negative corrosion potential. They suggested that the characteristics of the passive film changed in the medium and thus led to lowering the corrosion resistance. Also, S. Maruthamth et al. ${ }^{15}$, and Moos et al. ${ }^{17}$, have shown that the growth of microorganisms on the surface of the metal leading to biofilm formation which can affect the metal's corrosion process by producing a gel phase serving as a diffusion barrier and creating concentration cells for byproducts and corrosion products. In this study, the NiTi surface immersed in the artificial saliva in the presence of bacteria showed pitting corrosion ${ }^{18}$. This can be explained by the fact that $S$. mutans is an acidogenic bacteria that causes a decrease in $\mathrm{pH}^{13,19}$. Corrosion of orthodontic equipment by streptococcus mutans releases metal ions in patients, this release can cause metal allergy or even be toxic. More studies are needed to prove this point further.

\section{Conclusion}

The presence of $S$. mutans colonies on the surface of the orthodontic archwires adversely affects the corrosion resistance. Indeed, the decrease in $\mathrm{pH}$ induced by the acidic substances released by the metabolism of $S$. mutans can lead to the corrosion of titanium nickel frameworks and the release of dental alloy ions. This has a high-risk potential for toxicity in the human environment. Therefore, the maintenance of good oral hygiene and the use of adequate adjuvant methods during orthodontic treatment minimize the $\mathrm{pH}$ drop and improve the corrosion resistance of the NiTi dental alloys. 


\section{Conflict of Interest}

The authors declare that they have no conflict of interest.

\section{References}

1. J.R. Gurenlian, The Role of Dental Plaque Biofilm in Oral Health. Journal of Dental Hygiene. 2007, 81(5), 11.

2. R. Huang, M. Li, R.L. Gregory, Bacterial interactions in dental biofilm. Virulence. 2011, 2(5), 435-44.

3. 3. P.D. Marsh, A. Moter, D.A Devine, Dental plaque biofilms: communities' conflict and control. Periodontology, 2011, Feb, 55(1), 16-35.

4. D.A Spratt, J. Pratten, Biofilms and the Oral Cavity. Reviews in Environmental Science and Biotechnology. 2003, Jun 1, 2(2-4),109-120.

5. M. Matsumoto Nakono, Role of Streptococcus mutans surface proteins for biofilm formation, Japanese Dental Science Review, 2018, 54, 22-29.

6. P. Marsh, M. Martin, Oral microbiology. 5th ed. Edinburgh, New York, Elsevier, 2009, 222 pages.

7. P. Harikrishnan, T.S. Subha, V. Kavitha, A. Gnanamani, Microbial Adhesion on Orthodontic Ligating Materials, An in Vitro Assessment. Advances in Microbiology. 2013, 03(01), 108-114.

8. M. Rosentritt, S. Hahnel, G. Gröger, B. Mühlfriedel, R. Bürgers, G. Handel, Adhesion of Streptococcus mutans to various dental materials in a laminar flow chamber system. $\mathbf{J}$ Biomed Mater Res Part B Appl Biomater, 2008 Jul, 86(1), 36-44.

9. M. Sumita, T. Hanawa, I. Ohnishi, T. Yoneyama, Failure Processes in Biometallic Materials. In: I.M.O.R. Karihaloo, Comprehensive Structural Integrity, Pergamon, Oxford, 2003, 131-167.

10. I.H. Kim, H.S. Park, Y.K. Kim, K.H. Kim, T.Y. Kwon, Comparative short-term in vitro analysis of mutans streptococci adhesion on esthetic, nickel-titanium, and stainless-steel arch wires. The Angle Orthodontist. 2014, Jul, 84(4),
680-686.

11. G. Mabilleau, S. Bourdon, M.L. JolyGuillou, R. Filmon, M.F. Baslé, D. Chappard, Influence of fluoride, hydrogen peroxide and lactic acid on the corrosion resistance of commercially pure titanium, 2006 Jan, 2(1), 121-129.

12. J.C.M. Souza, P. Ponthiaux, M. Henriques, R. Oliveira, W. Teughels, J.P. Celis, and al. Corrosion behaviour of titanium in the presence of Streptococcus mutans. Journal of Dentistry, 2013, Jun, 41(6), 528-534.

13. L. Bahije, H. Benyahia, S. El Hamzaoui, M. Ebn Touhami, R. Bengueddour, W. Rerhrhaye and al. Behavior of NiTi in the presence of oral bacteria: Corrosion by Streptococcus mutans. International Orthodontics. 2011, Mar, 9(1), 110-119.

14. T. Fusayama, T. Katayori, S. Nomoto, Corrosion of gold and amalgam placed in contact with each other. Journal of Dental Research, 1963, 42, 1183-1197.

15. S. Maruthamuthu, A. Rajasekar, S. Sathiyanarayanan, N. Muthukumar, N. Palaniswamy, Electrochemical behaviour of microbes on orthodontic wires. Current science, 2005, 89(6), 988.

16. J.C. Chang, Y. Oshida, R.L. Gregory, C.J. Andres, T.M. Barco, BDt elEctrochemical study on microbiology-related corrosion of metallic dental materials. Biomed Mater Eng. 2003,13(3), 281-295.

17. O. Moos, P. Gümpel, Comparison of the microbiological influence on the electrochemical potential of stainless steel between macro- and micro-areas of specimens. Electrochimica Acta. 2008, Dec,54(1), 53-59.

18. I.H. Liu, T.M. Lee, C. Y. Chang, C.K. Liu, Effect of load deflection on corrosion behavior of NiTi wire. Journal of Dental research 2007, 86(6), 539-597.

19. J.A. Lemos, S.R. Palmer, L. Zeng, Z.T. Wen, J.K. Kajfasz, I.A. Freires, J. Abranches, L.J. Brady, the Biology of Streptococcus mutans. Microbiol Spectr., 2019, jan, 7(1). doi: 10.1128/microbiolspec.GPP30051-2018. 